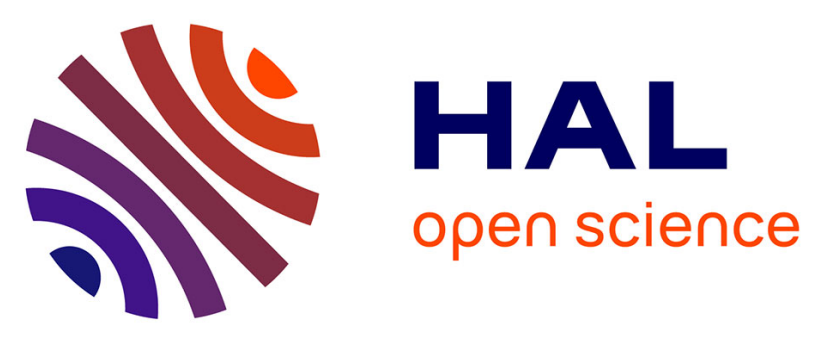

\title{
Impact of external temperature distribution on the convective mass flow rate in a vertical channel - A theoretical and experimental study
}

Martin Thebault, John Reizes, Stéphanie Giroux-Julien, Victoria Timchenko, Christophe Menezo

\section{To cite this version:}

Martin Thebault, John Reizes, Stéphanie Giroux-Julien, Victoria Timchenko, Christophe Menezo. Impact of external temperature distribution on the convective mass flow rate in a vertical channel A theoretical and experimental study. International Journal of Heat and Mass Transfer, 2018, 121, pp.1264-1272. 10.1016/j.ijheatmasstransfer.2018.01.081 . hal-01727714

\author{
HAL Id: hal-01727714 \\ https://hal.science/hal-01727714
}

Submitted on 13 Mar 2018

HAL is a multi-disciplinary open access archive for the deposit and dissemination of scientific research documents, whether they are published or not. The documents may come from teaching and research institutions in France or abroad, or from public or private research centers.
L'archive ouverte pluridisciplinaire HAL, est destinée au dépôt et à la diffusion de documents scientifiques de niveau recherche, publiés ou non, émanant des établissements d'enseignement et de recherche français ou étrangers, des laboratoires publics ou privés. 


\section{Impact of external temperature distribution on the convective mass flow rate in a vertical channel - A theoretical and experimental study.}

Martin Thebault a,b, John Reizes ${ }^{b}$, Stéphanie Giroux--Julienª, Victoria Timchenko ${ }^{b}$, Christophe Ménézo ${ }^{\circ}$

a Univ Lyon, CNRS, INSA-Lyon, Université Claude Bernard Lyon 1, CETHIL UMR5008, F69621, Villeurbanne, France

b School of Mechanical and Manufacturing Engineering, UNSW-Sydney, Sydney 2052, Australia

- University Savoie Mont-Blanc, LOCIE UMR CNRS 5271, Campus Scientifique Savoie Technolac - F-73376, Le Bourget-du-Lac, France

Keywords:

natural convection; vertical open channel uniformly heated; external temperature stratification; mass flow rate; experimental; 


\section{Nomenclature}

$\begin{array}{ll}A & \text { heated surface } \\ A_{r} & \text { aspect ratio } \\ C_{p} & \text { specific heat } \\ D & \text { distance between the plates } \\ g & \text { acceleration due to gravity } \\ H & \text { height of the channel } \\ k & \text { thermal conductivity } \\ \dot{m} & \text { mass flow rate } \\ P r & \text { Prandtl number } \\ \dot{q} & \text { heat flux density } \\ \dot{\mathrm{Q}} & \text { heat power } \\ R a & \text { Rayleigh number } \\ S & \text { stratification parameter } \\ T & \text { temperature } \\ T_{0} & \text { reference temperature } \\ \mathrm{W} & \text { width of the channel } \\ Z & \text { altitude relative to the channel inlet }\end{array}$

\section{Greek Symbols}

$\begin{array}{ll}\alpha & \text { thermal diffusivity } \\ \beta & \text { coefficient of thermal expansion } \\ \rho & \text { density } \\ v & \text { kinematic viscosity } \\ \delta T & \text { external temperature gradient } \\ \Delta T & \text { temperature difference }\end{array}$

\section{Subscripts}

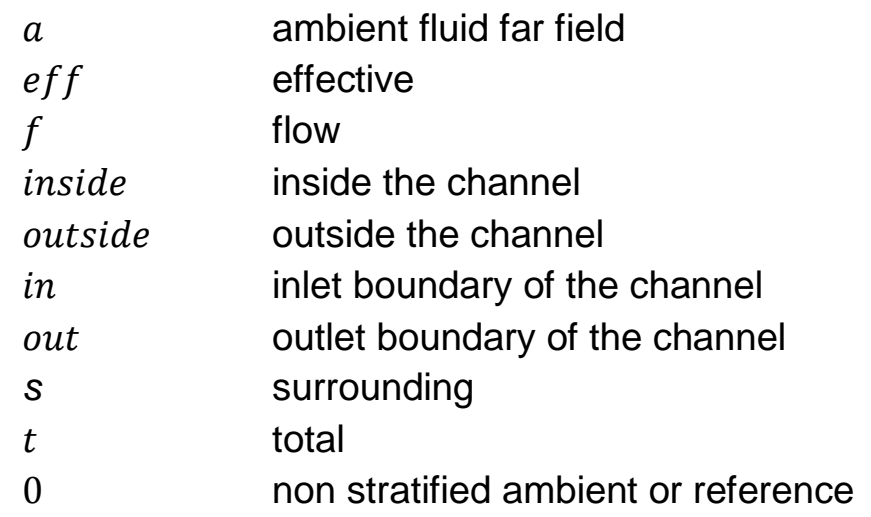




\section{Abstract}

Many works have been performed on heated vertical rectangular open-ended channels. While in most cases, thermal fields are quite well predicted or reproducible, there were often large unexplained variations in the experimental flow rate for apparently the same conditions. An experimental and theoretical investigation has therefore been carried out to identify the effect of external thermal stratifications on the flow rate. Four values of steady and uniform heat flux, equivalent to Rayleigh numbers between $2.9 \times 10^{4}$ and $1.6 \times 10^{8}$ were imposed experimentally either on one or both sides of a vertical rectangular channel, with various ambient thermal gradients external to the channel. It was observed that the mass flow rate was significantly reduced as the positive upward, external thermal gradient increased. A theoretical model of the phenomenon was also developed. There is an excellent agreement between the theoretically predicted and experimentally measured mass flow rates. This clearly highlights that external temperature distributions are key driving factors and their influence is accurately quantified in this work.

\section{Introduction}

Over the last decade and a half, the increasing concerns regarding the environmental issues due to climate change has necessitated a rethinking of the management and methods of energy production and consumption. Given that the daily incident solar energy on the global landmass is greater than the annual worldwide energy consumption, harvesting of solar energy is one of the most promising solutions. To that extent, among other technologies, passively ventilated solar photovoltaic arrays integrated in buildings (BIPV) - the so-called double façades - have been developed. These components use solar energy to generate electricity, whilst the concomitant, but unwanted thermal heating of the arrays produces natural convective flows in the space between the PV façade and the wall enclosing the building. This natural ventilation cools the PV arrays, thereby increasing their efficiency [1], with the added advantage that the flow can also be used for heating or night cooling the building.

The flow in the air gap between a PV façade and the wall of a building is analogous to that of the flow in an open-ended heated channel. As a result, natural convection in small-scale open-ended heated channels in laboratory settings has been extensively studied. One of the main objectives of these studies was the prediction of mass flow rate, which is strongly correlated with the other indicators of component performance. Analytical approaches have been developed to predict the mass-flow rate for moderate Rayleigh numbers [2]-[8] while correlations have been developed from numerically generated data and from experimental 
results for turbulent natural convection at higher Rayleigh numbers [9]-[11]. Khanal and Lei [12] reviewed the relationship between the mass flow rate and the Rayleigh number. They both showed with Yilmaz and Fraser [13] that the analytic results were usually in good agreement with the data from numerical models. However, neither numerical nor analytic models are in good agreement with experimental data, especially when it comes to moderate Rayleigh numbers, where large discrepancies exist [3], [14], [15].

The differences between numerically generated and experimentally obtained data have been attributed to the inadequacies of the turbulence models when Reynolds Averaged NavierStokes solvers are used [13], to the inadequacies of the subgrid models when a Large Eddie Simulation is employed [16] or to three-dimensional effects in two-dimensional (2-D) simulations [17]. Another source of differences is attributed to the neglect or inappropriate modelling of radiation [18], [19] and the lack of knowledge about the actual boundary conditions [20], [21]. The necessity to improve the knowledge and modelling of the openboundary conditions was demonstrated by Lau [14], [22] or by Desrayaud et al. [23]. Experimentally, difficulties arise from large measurement uncertainties and from the difficulty of "identically" replicating experimental conditions [15], thus obtaining experimental results which are noticeably different for apparently the same conditions. One parameter, the external temperature gradient, although measured by some researchers [24], [25], was not systematically investigated by them. This could also have been the origin of the discrepancies, as it is known that it has a significant effect on natural convective flows on isolated plates.

The impact of surrounding ambient temperature stratification had been studied more extensively in the case of natural convection adjacent to a vertical plate. In 1967 Cheesewright [26] first developed similarity solution for steady laminar natural convective flows adjacent to vertical isothermal plate in non-uniform ambient temperatures. His work started after he noticed significant differences between analytical models and experimental measurements. In an excellent theoretical and experimental paper Jaluria and Gebhart [27] investigated the effect of linear thermal ambient stratification on steady laminar buoyancyinduced flows adjacent to a vertical uniformly heated plate. They showed that an increase of the positive upward ambient temperature gradient results in a decrease of the induced velocity. They reasoned that this was caused by the fact that as the ambient temperature increases downstream, the temperature difference between the local ambient temperature at a particular elevation and the temperature of the upward moving fluid in the boundary layer at the same elevation is less than it would have been if the ambient temperature had been uniform, with the result that a reduced buoyancy led to lower induced velocities. 
However, in studies involving natural convection in open-ended channels, the impact of the thermal stratification has often been neglected or underestimated although it is been reported. Garnier [28] numerically modelled unsteady laminar natural convection induced in a channel which is uniformly heated on one side in a confined adiabatic cavity of various sizes. He showed that once the thermal stratification develops and reaches the top of the channel, the induced mass flow rate decreases. More recently Ramalingom and Bastide [29] also numerically modelled a uniformly heated channel introducing a temperature difference in the ambient fluid between the inlet and the outlet corresponding to a stable stratification in the ambient fluid. The results show as well a decrease in the induced mass flow rate.

Experimentally the impact of the temperature gradient had been known for many years though not specifically investigated. Haaf et al. [30] in a pilot project on a solar chimney, underlined and recorded its "favourable or unfavourable effect". The only experimental work found in the literature that highlights the dependence of the mass flow rate in a uniformly heated vertical channel on the external stratification is from Daverat et al. [31] who observed a very significant diminution in the mass flow rate as a function of an increase in the positive upward external thermal gradient. However, in experimental studies with uniform heat fluxes in vertical open-ended channels, when thermal stratification is reported, more commonly its impact has either been neglected [24], [25] or avoided by doing experiments before stratification has developed [32] or by using an active regulation system to ensure that the ambient temperature is homogeneous [33]. It follows that the effect of an external thermal gradient needs to be fully investigated.

The aim of this paper is therefore to determine whether there is the strong link between the external temperature stratification and the induced mass flow rate in a uniformly heated vertical channel, and to establish a relation between them. An experimental study has therefore been performed to generate data at different constant Rayleigh numbers with various external temperature distributions. A one-dimensional theory has been developed to predict the mass flow rate as a function of the external temperature gradient. The model predictions are compared with the experimental results mentioned above as well as those of Daverat et al. [31].

\section{Experimental apparatus and measurement conditions}

\subsection{Room and channel geometry}

The experimental apparatus is located in a $6.6 \mathrm{~m}$ high, $4.6 \mathrm{~m}$ wide and $7.0 \mathrm{~m}$ long laboratory; in the basement of the CETHIL laboratory in Lyon, France. The experimental channel, presented in Fig. 1, consists of two parallel vertical walls $1.50 \mathrm{~m}$ high $0.70 \mathrm{~m}$ wide 
and $0.10 \mathrm{~m}$ apart, located $0.75 \mathrm{~m}$ above the floor. They are composed of $12 \mathrm{~cm}$ thick insulating polyurethane blocks of thermal conductivity $0.027 \mathrm{~W} / \mathrm{mK}$, embedded in wooden frame. The channel is closed on both lateral sides by two vertical Plexiglas sheets to avoid lateral infiltration of air and allow optical access to the channel. The inside surface of each of the wide channel walls is covered by 15 independently controlled stainless steel foil heaters, each $10 \mathrm{~cm}$ wide, $50 \mu \mathrm{m}$ thick and $70 \mathrm{~cm}$ long. The emissivity of the foils is 0.092 and the thermal conductivity is $13 \mathrm{~W} / \mathrm{mK}$. The leading edges of the two wide plates have $30^{\circ}$ chamfers at the inlet in order to guide the fluid and reduce inlet turbulence. A horizontal $0.70 \mathrm{~m} \times 1 \mathrm{~m}$ artificial ceiling was placed $75 \mathrm{~cm}$ above the outlet. This geometry configuration was designed in order to have the same boundary condition above and below the channel and to reduce the size of the computational domain and thereby the CPU time needed for numerical simulations.

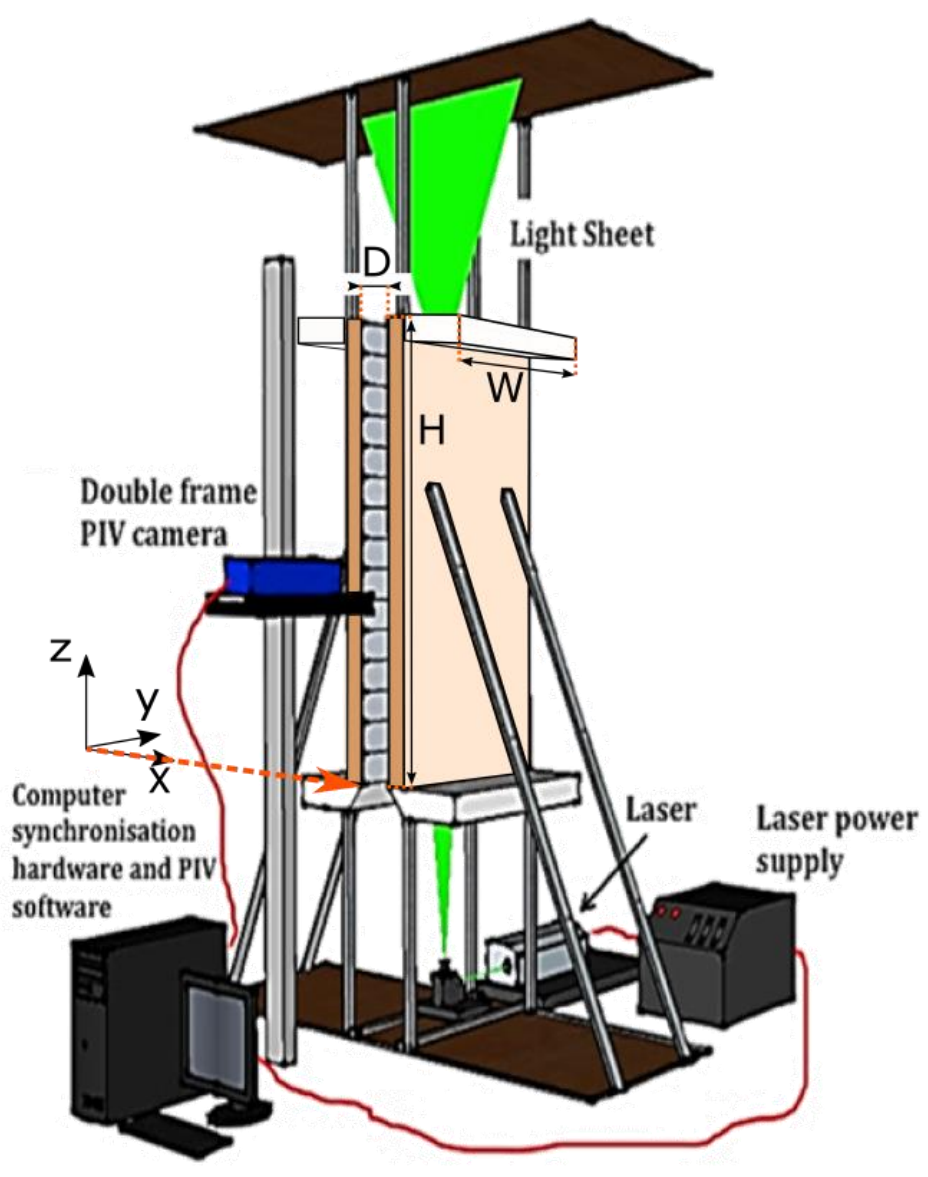

Fig. 1. Scheme of the experimental apparatus

\subsection{Temperature measurements}

For temperature acquisition, 75 thermocouples were placed along the vertical mid-plane line $y / W=0.5$ in which $y$ is defined in Fig. 1 and $W$ is the width of the wide walls. The 
thermocouples were placed inside the insulation and in intimate contact with the heated foil. This arrangement gives five measurement points per foil and prevents thermocouples intruding into the flow region. Additional thermocouples were positioned in the insulation so as to evaluate heat losses. Seven thermocouples were located at the inlet in order to obtain the mid-plane inlet temperature profile. Finally thermocouples were located near the outlet, outside the channel. All thermocouples were standard K-types thermocouples made with $120 \mu m$ wire.

Ambient thermal conditions were evaluated with five thermocouples located at $0.1 ; 0.7$; $1.3 ; 1.7$ and $2.3 \mathrm{~m}$ from the floor on the same on the same vertical pole, $1.5 \mathrm{~m}$ from the channel. The ambient vertical temperature gradient, $\delta T(\mathrm{~K} / \mathrm{m})$ was then defined as the slope of the linear regression of these measurements.

All thermocouples were calibrated individually in a constant temperature water bath before being installed. The calibration procedure is given by Sanvicente [15]. Thermocouples measurement uncertainty was evaluated at $\pm 0.05 \mathrm{~K}$. The temperature acquisition rate was $10 \mathrm{~Hz}$.

\subsection{Velocity flow field measurement}

Velocity fields on the centre plane, $y / W=0.5$ were obtained with the Particle Image Velocimetry (PIV) method. The apparatus and methodology had already been described and characterized in detail by Sanvicente et al. [25] and main features are summarized below. The PIV system was composed of a pulsed Nd: YAG laser emitting at $532 \mathrm{~nm}$. The standard set of lenses to get sheets was used. A Charge-Coupled Device (CCD) camera was employed for image acquisition; recording image with a resolution of $540 \times 2048$ pixels. The acquisition window corresponded to a section of the flow to a $100 \mathrm{~mm}$ wide by $380 \mathrm{~mm}$ high area. Experiments are conducted by seeding the flow with droplets of silicon oil Di-EthylHexyl-Sebacat. The generated particles had of diameter smaller than $1 \mu \mathrm{m}$ and a density of $912 \mathrm{~kg} / \mathrm{m}^{2}$ and have sufficient light scattering capability as well as a minimal slip between the fluid and the particle [34]. A standard PIV method of double frame was used in which the two images were acquired $1 \mathrm{~ms}$ apart. This time has been set so that particles did not displaced by more than $1 / 4$ of the interrogation window between the two frames. The acquisition frequency employed was $10 \mathrm{~Hz}$.

Raw image were post-processed using PIVlab [35], a toolbox developed in the Matlab environment. Cross correlation technique had been used so as to obtain a snapshot of the velocity vector field. Data analysis is then done using sub-routines in Matlab. 
In this paper, only the measurements made in the inlet region are discussed. During each measurement session, 8000 double images were acquired, which correspond to a measurement period of $14 \mathrm{~min}$. This measurement period provide a reliable average of the main quantities of the flow [25]. The systematic errors, related to the laser, the seeding procedure, the camera calibration and the post processing were estimated at $\pm 0.015 \mathrm{~m} / \mathrm{s}$.

\subsection{Ambient conditions in the room}

\subsubsection{Sources of disturbances}

The experimental procedure for a measurement session has been described in details by Vareilles [36] and Sanvicente [15]. Before each measurement the channel was operated at the nominal power for four hours in order to ensure thermal steady conditions inside the walls. All temperature and velocity measurements devices needed to be warmed up and were also switched on some times before being used.

Indoor temperatures were not controlled and allowed to evolve freely. Indeed an active control of them would introduce perturbations of temperature and velocity fields. Unfortunately there were parasitic heat sources and velocity disturbances in the room such as the laser power supply or the PIV computer. In order to minimize their impact on the flow they have been placed as far as possible from the channel.

\subsubsection{Experimental conditions}

For the great majority of the cases the room temperature distribution could be approximated by a linear distribution with a coefficient of determination $\mathrm{R}^{2}$, calculated from least square analysis, greater than 0.95 . The coefficient of determinations of thermal gradients are plotted in Fig.2. The two points with a coefficient of determinations $\mathrm{R}^{2}$ lower than 0.9 corresponds to linear approximations calculated from too low spatial definition associated to a weak stratification and relatively high floor temperature. 


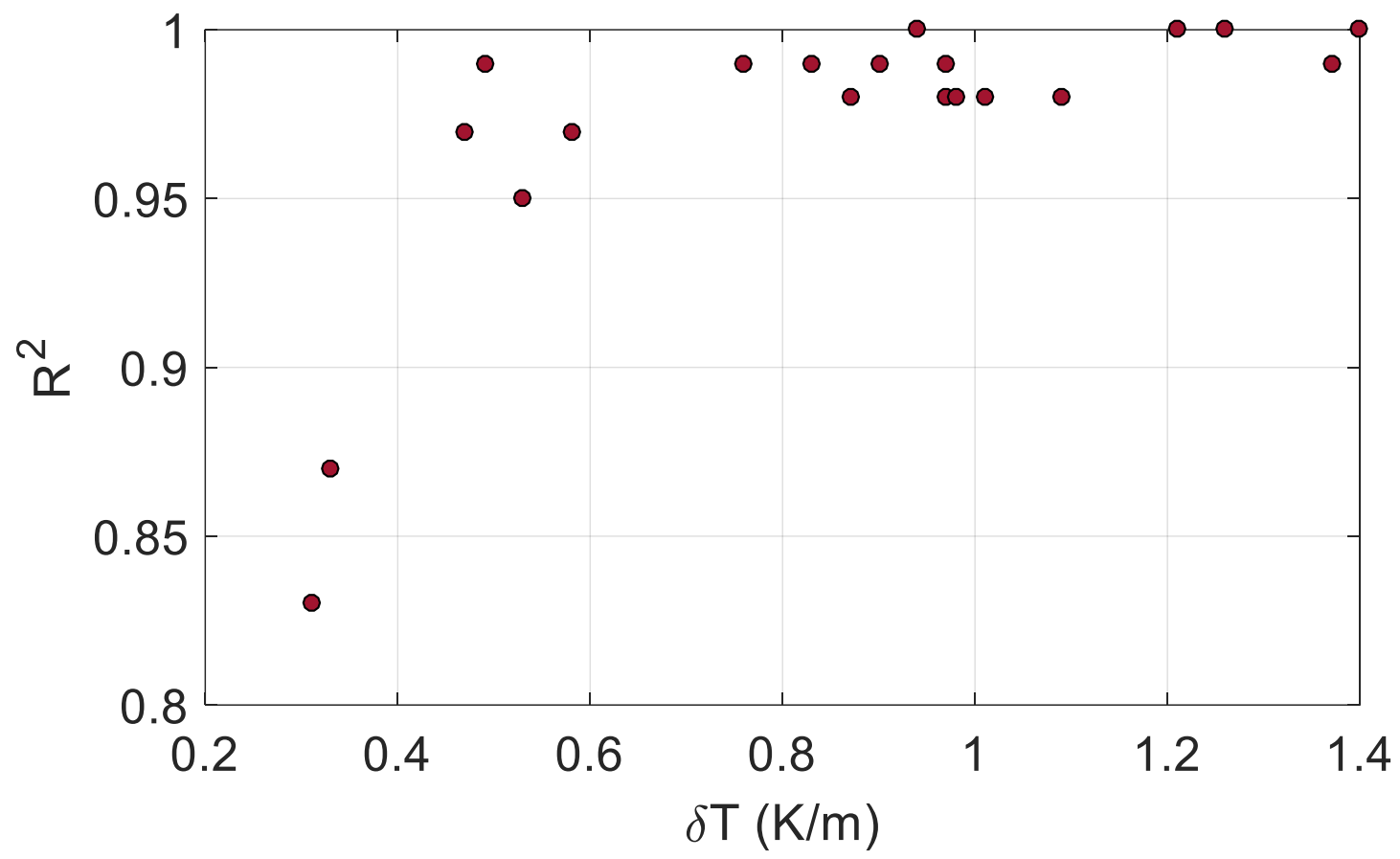

Fig. 2. Coefficient of determination, $R^{2}$ of the temperature gradients $\delta T$

It has been found that on average, the temperature gradient in the laboratory increased by $0.01 \mathrm{~K} / \mathrm{m}$ per hour during the test periods. Since the measurements took approximately a quarter-of-an-hour, the temperature gradient in the room was constant during the measurement period.

The average temperature change in the room during one measurement is $\pm 0.1 \mathrm{~K}$. Because this change was also small, conditions could still be assumed to remain constant during the measurement period.

During the whole test period, the ambient room temperature ranged between 17 and $23^{\circ} \mathrm{C}$.

\section{Experimental results}

\subsection{Cases studied}

Natural convective flows in a vertical heated open-ended channel are usually characterized by three non-dimensional parameters, namely, the Rayleigh number, $R a$, the Prandtl number, $\mathrm{Pr}$, and the aspect ratio $A_{r} . R a$ is defined as

$$
R a=\frac{g \beta q_{0} D^{4}}{\alpha v k}
$$


in which $g\left(\mathrm{~m} / \mathrm{s}^{2}\right)$ is the gravitational acceleration, $\beta(1 / \mathrm{K})$ is the coefficient of thermal expansion, $q_{0}\left(\mathrm{~W} / \mathrm{m}^{2}\right)$ is the heat flux, $D(\mathrm{~m})$ is the distance between the wide plates, $\alpha\left(\mathrm{m}^{2} / \mathrm{s}\right)$ is the thermal diffusivity, $v\left(\mathrm{~m}^{2} / \mathrm{s}\right)$ is the kinematic viscosity, $k(\mathrm{~W} /(\mathrm{m} \mathrm{K}))$ is the thermal conductivity. In the remainder of the paper, the subscript 0 refers to reference quantities that are defined in the case of an absence of thermal stratification in the ambient fluid outside the channel.

The Prandtl number is expressed as

$$
\operatorname{Pr}=\frac{v}{\alpha}
$$

and the aspect ratio is given by $A_{r}=\frac{D}{H}$ in which $H(\mathrm{~m})$ is the height of the channel.

It should be noted that the Rayleigh number in equation is defined without reference to an external temperature distribution.

Three values of Rayleigh number have been investigated; corresponding to the three injected electrical powers $\dot{Q}_{t}(\mathrm{~W}), 100,230$ and $500 \mathrm{~W}$ used in the experiments. The subscript $t$ indicates total injected electrical power. The heated foils have a uniform electrical energy heat flux supplied on one side of the channel. Sanvicente [15] and Vareilles [36], who used the same channel as the present authors, estimated that around $5 \%$ of the supplied electrical power was lost by conduction through the insulation and by radiation directly to the surroundings. The net heat input, $\dot{Q}_{0}(\mathrm{~W})$ transferred to the flowing fluid, was calculated by subtracting the estimate of these losses from the total electrical power $\dot{Q}_{t}$.

The losses, at a given injected electrical power, have, however, been assumed to be independent of an external temperature distribution. Consequently the net heat input, $\dot{Q}_{0}$ is independent of any external temperature stratification. The resulting main parameters are listed in Table 2.

Table 2 Main parameters corresponding to experimental measurements

\begin{tabular}{cccc}
\hline Item & \multicolumn{3}{c}{ Value } \\
\hline Case & $100 \mathrm{~W}$ & $230 \mathrm{~W}$ & $500 \mathrm{~W}$ \\
$\dot{Q}_{t}(\mathrm{~W})$ & 100 & 230 & 500 \\
$\dot{Q}_{0}(\mathrm{~W})$ & 95 & 218.5 & 475 \\
$R a$ & $3.0 \times 10^{7}$ & $6.9 \times 10^{7}$ & $1.6 \times 10^{8}$ \\
\hline
\end{tabular}




\subsection{Influence of the external temperature stratification}

The average mass flow rate in the channel can be estimated, on the assumption that the flow is two-dimensional, using the centre plane time-averaged velocity and temperature profiles measured at the inlet. This may lead to a slight error of the mass flow rate as threedimensional effects have been neglected.

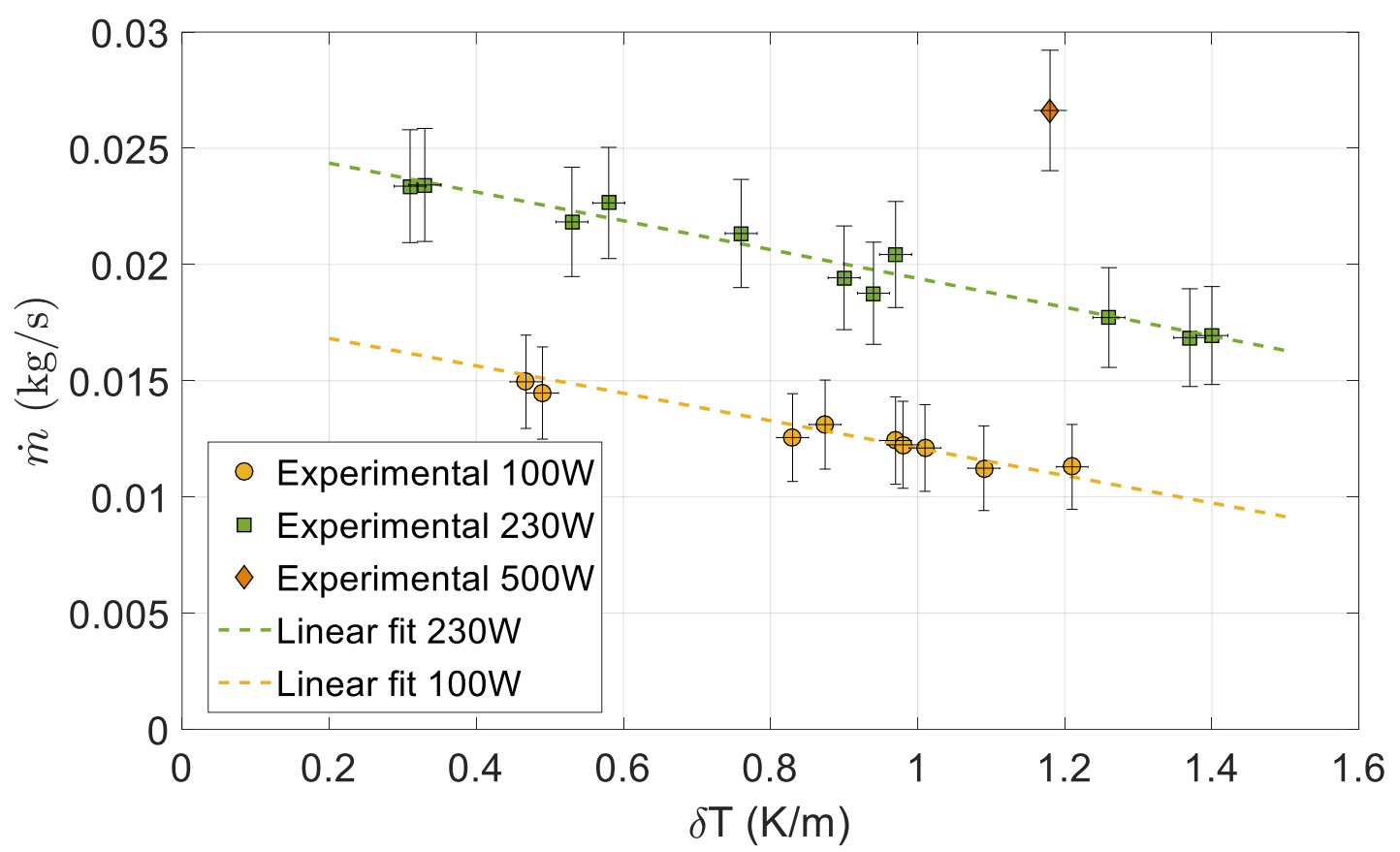

Fig. 3. Time-averaged mass flow rate, $\dot{m}$, against the thermal gradient within the room $\delta T$, for three different injected powers of $\dot{Q}_{t}=100,230$ and 500W, and their associated error bars. The linear curve of best fit has been plotted as dashed line for the cases 100W and 230W respectively

In Fig. 3 the time-averaged mass flow rate, $\dot{m}(\mathrm{~kg} / \mathrm{s})$, is plotted as a function of the external temperature gradient, $\delta T$, for the three cases studied. Each point corresponds to one measurement as described in section 2.3. The associated error bars, calculated from the experimental uncertainties are plotted for each measurement. It is clear from Fig. 3 that the mass flow rate is a function of the external temperature gradient. Where possible, a linear curve of best fit had been plotted so as to highlight the relationship.

Attempts at using dimensional analysis to provide a correlation for collapsing the two curves and the single point obtained at $500 \mathrm{~W}$, onto one relationship of non-dimensional parameters proved unsuccessful. As a consequence a one-dimensional theory was developed in an attempt to obtain better understanding of the phenomenon and allow all the available data to collapse on a single curve. 


\section{Theoretical considerations}

A relationship is developed between the mass flow rate generated in the vertical channel at a constant heat flux and the vertical temperature distribution in the surroundings. This theory is based on the following assumptions:

- The flow induced by natural convection is established and in a steady state,

-The channel is flowing full and the flow is considered to be one-dimensional and ascendant,

-The vertical channel is embedded in a stagnant atmosphere far-field, with a vertical constant positive temperature gradient $\delta T(\mathrm{~K} / \mathrm{m})$, in the ascending $z$ direction (see Fig. 1 for the axis direction).

The reference temperature $T_{0}(\mathrm{~K})$, is here defined as the far field ambient temperature at the same elevation as the inlet. It follows that the temperature in the far-field ambient fluid is given at any height $z(m)$ by

$$
T_{a}(z)=T_{0}+z \delta T,
$$

in which the subscript $a$ indicates the ambient fluid in the, far-field.

The average temperature distribution in the mid-plane $(y / W=0.5)$ of the apparatus described in section 2.1 and the notation used below is presented Fig.4. The background colour (available online), from white to red (dark grey) represents a simplification of the temperature distribution patterns in a 2-D plane of the channel. The red (grey) rectangle represents the heated wall whilst white rectangles represent adiabatic walls; black arrows approximately indicate flow pattern. 


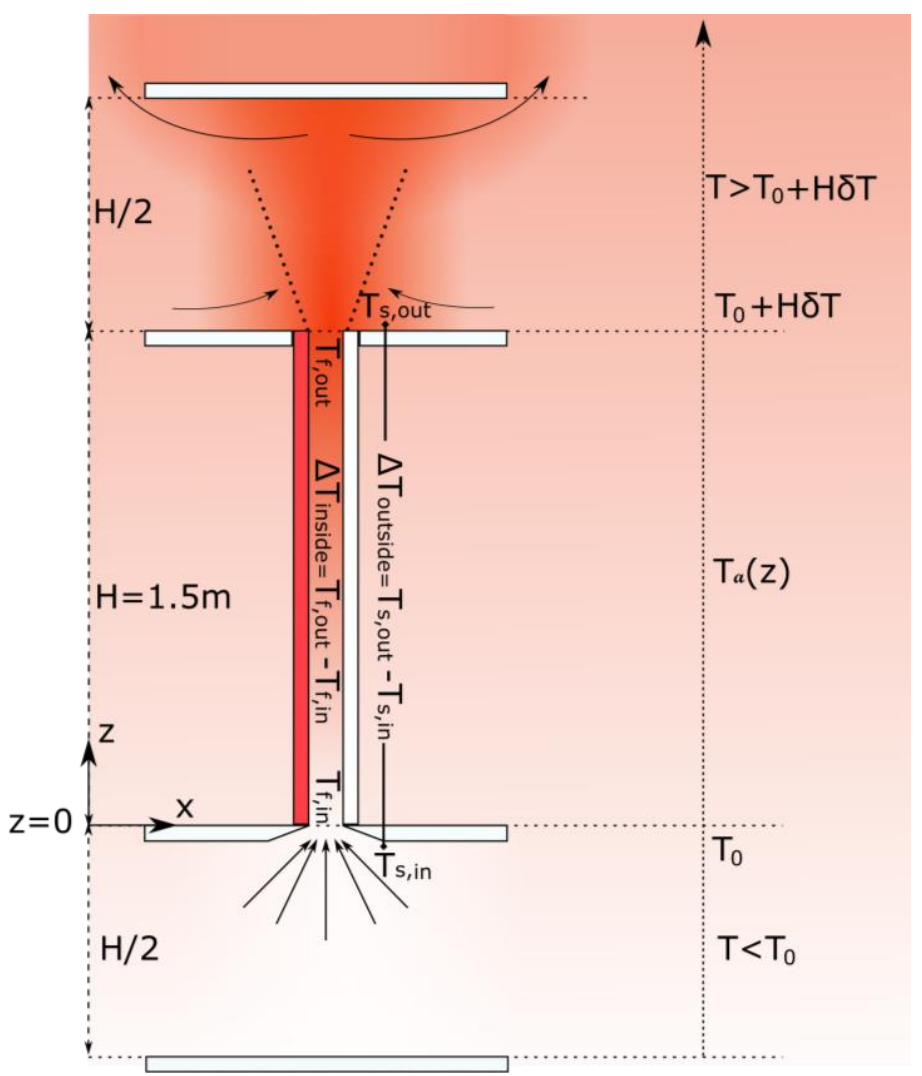

Fig. 4. Schematic diagram of the mid-plane flow in the apparatus and its associated simplified temperature distribution represented by the background colour (colour available online). The plain black arrows approximately indicate flow pattern and the red rectangle represents the heated wall whilst white rectangles are adiabatic walls.

\subsection{Definition of the local temperatures at the open-boundaries of the channel and their relations in the buoyant vertical channel flow}

Let $T_{f, \text { in }}(\mathrm{K})$ be the temperature of the fluid entering the channel and $T_{s, i n}(\mathrm{~K})$ the temperature outside the channel, in the immediate neighbourhood of the inlet of the channel. $T_{f, \text { out }}(\mathrm{K})$ and $\rho_{f, \text { out }}\left(\mathrm{kg} / \mathrm{m}^{3}\right)$ denotes the temperature and the density of the fluid exiting the channel respectively. $T_{s, \text { out }}(\mathrm{K})$ and $\rho_{s, \text { out }}\left(\mathrm{kg} / \mathrm{m}^{3}\right)$ are respectively the temperature and the density of the fluid, outside the channel, in the immediate surrounding of the outlet of the channel, but not of the exiting fluid flow.

Due to the heat input inside the channel, an upward directed flow is generated with a mass flow rate $\dot{m}(\mathrm{~kg} / \mathrm{s})$.

At the inlet boundary of the channel, if heat conduction and diffusion are considered to be negligible so that it can be assumed that 


$$
T_{f, \text { in }} \approx T_{s, i n}
$$

Regarding the outlet, since the motion which results from buoyancy force is ascending and one dimensional, the density of the fluid exiting the channel $\rho_{f, \text { out }}$ is lower than that of the fluid in the vicinity of the outlet, outside the channel, $\rho_{s, \text { out }}$ so that

$$
\rho_{f, \text { out }} \leq \rho_{\text {s,out }}
$$

Considering now the Boussinesq approximation, which validity domain had been discussed amongst others by Gray and Giorgini [37], $\rho\left(\mathrm{kg} / \mathrm{m}^{3}\right)$ the density of the fluid at a temperature $T(\mathrm{~K})$ can be expressed as

$$
\rho=\rho_{0}\left(1-\beta\left(T-T_{0}\right)\right)
$$

Where $\rho_{0}\left(\mathrm{~kg} / \mathrm{m}^{3}\right)$ is the reference density of the fluid taken at $T_{0}$,

In that context Eq. (5) can be expressed as the temperature difference

$$
T_{f, \text { out }} \geq T_{\text {s,out }} \text {. }
$$

Defining $\Delta T_{\text {inside }}(\mathrm{K})$, the temperature difference between the fluid exiting and the fluid entering the channel, and $\Delta T_{\text {outside }}(\mathrm{K})$, the temperature drop, in the immediate surrounding region outside the channel, between the top and the bottom of the channel, then by definition

$$
\Delta T_{\text {inside }}=T_{f, \text { out }}-T_{f, \text { in }} \text {, and } \Delta T_{\text {outside }}=T_{s, \text { out }}-T_{s, \text { in }}
$$

From Eq. (4) and Eq. (7), it follows that an inherent consequence when an upward flow occurs in this configuration is that

$$
\Delta T_{\text {inside }} \geq \Delta T_{\text {outside }}
$$

Therefore the inside temperature difference $\Delta T_{\text {inside }}$ can be written as

$$
\Delta T_{\text {inside }}=\Delta T_{\text {outside }}+\Delta T_{\text {eff }}
$$

with $\Delta T_{e f f}$ corresponding to the effective temperature rise. By definition,

$$
\Delta T_{e f f} \geq 0 .
$$

\subsection{The temperatures in the outside vicinity of the open boundaries of the channel, and their dependence on the far field conditions in a linearly stratified ambient environment}


In order to estimate the boundary conditions at the open ends of the channel, the far-field conditions have been usually used. In that case, the temperature drop in the outside vicinity of the open-boundaries, $\Delta T_{\text {outside }}$, defined in the previous section, is equal to $H \delta T$, the temperature drop in the far-field ambient over the height of the channel. However, the choice of the inlet and outlet boundary conditions currently remains an open question. Indeed, it has been showed in numerous numerical studies [17], [20], [23], [28] that using far-field conditions leads to an overestimate of the induced mass flow rate, compared with the one calculated from experimental results. An alternative approach is proposed in this section for the case of a thermally stratified ambient atmosphere. To that extent inlet and outlet entrainment regions are introduced, outside the channel, in the vicinities of the openboundaries. These bottom and top regions, the temperature of which are respectively $T_{s, \text { in }}$ and $T_{s, \text { out }}$, link the channel open-boundaries and the far-field conditions.

Considering the I-type geometry, defined by Manca et al. [38], of the experimental device Fig. 1, the horizontal walls on each side of the channel inlet constraint the fluid in the inlet entrainment region to be entrained from levels lower than the entrance. Therefore the average temperature of the fluid in that region $T_{s, i n}$ is lower or at most equal than that occurring in the far-field at the level of the channel entry $T_{0}$ so that if

$$
\Delta T_{\text {inlet }}=T_{s, i n}-T_{0}
$$

Then

$$
\Delta T_{\text {inlet }} \leq 0
$$

With $\Delta T_{\text {inlet }}(K)$, the temperature difference between the inlet entrainment region and the farfield temperature at the level of the inlet.

Similarly at the outlet, the fluid in the entrainment region is entrained from levels higher than the outlet so that $T_{s, \text { out }}$ is higher or at least equal to the temperature far-field at the same height. If $\Delta T_{\text {outlet }}$ denotes the excess in temperature of the entrained fluid over the temperature pertaining at the same level as the outlet of the channel so that

$$
\Delta T_{\text {outlet }}=T_{s, \text { out }}-\left(T_{0}+H \delta T\right)
$$

Then

$$
\Delta T_{\text {oulet }} \geq 0
$$

Therefore by substituting Eqs. (13) and (15) in the expression of $\Delta T_{\text {outside }}$, Eq. (8) becomes 


$$
\Delta T_{\text {outside }}=\Delta T_{\text {outlet }}-\Delta T_{\text {inlet }}+H \delta T,
$$

with Eqs. (14) and (16) giving

$$
\Delta T_{\text {outlet }}-\Delta T_{\text {inlet }} \geq 0
$$

The temperature $T_{s, i n}$ results from a mixing of fluid entrained at levels between the floor and the inlet height. As a first approximation, suppose that $T_{s, i n}$ is equal to the temperature, far field, at mid height between the floor and the inlet of the channel resulting in

$$
T_{s, \text { in }} \approx T_{0}-\frac{1}{4} H \delta T
$$

And

$$
\Delta T_{\text {inlet }} \approx-\frac{1}{4} H \delta T
$$

Similarly at the outlet, because of the horizontal walls, the entrained fluid arriving from regions above the exit would be warmer than the far-field ambient fluid at the level of the channel outlet. Further, because of the semi-confined configuration stemming from the presence of the artificial ceiling, $T_{s, o u t}$ is assumed to correspond to the temperature, in the ambient, at the level half way between outlet and the artificial ceiling, namely so that

$$
T_{s, \text { out }} \approx T_{0}+H \delta T+\frac{1}{4} H \delta T
$$

And

$$
\Delta T_{\text {outlet }} \approx \frac{1}{4} H \delta T
$$

It follows that under these simple assumptions,

so that $\Delta T_{\text {outside }}$ can be estimated as

$$
\Delta T_{\text {outlet }}-\Delta T_{\text {inlet }} \approx \frac{1}{2} H \delta T,
$$

$$
\Delta T_{\text {outside }} \approx \frac{3}{2} H \delta T \text {. }
$$

The assessment for $\Delta T_{\text {inlet }}$ and $\Delta T_{\text {outlet }}$ proposed in this subsection is based on the geometric characteristics of the studied channel. These assessments are confronted to an experimental validation for the range of Rayleigh numbers studied in section 5 . Note that these assessments are specific to this channel configuration and would require new evaluation in the case of different channel geometries.

The estimates made in the present section are not valid anymore when there is no heat input i.e. no flow inside the channel, as in that particular case, there are no entrainment region at 
the open boundaries so that the temperature distribution inside the channel is the same as the far-field ambient temperature distribution.

\subsection{Reference case of a non-stratified ambient}

In order to obtain the analytic relation between the mass flow rate and the external thermal stratification, the case of a non-stratified ambient, $\delta T=0$, is first considered and taken as the reference case.

In that case, by applying the first law of thermodynamic, the energy transfer rate inside the channel can be estimated as

$$
\dot{Q}_{0}=\dot{m}_{0} C_{p} \Delta T_{0},
$$

With $\dot{m}_{0}=\dot{m}(\delta T=0)$ and $\Delta T_{0}=\Delta T_{\text {inside }}(\delta T=0)$ being respectively the mass flow rate and the internal temperature rise through the channel when there is no stratification in the ambient. In that case, the operating point $\left(\dot{m}_{0}, \Delta T_{0}\right)$ of the channel results from the balance between the stack effect inside the channel, the pressure drop between the top and the bottom of the channel and the viscous friction at the wall. This operating point can be estimated experimentally, numerically or by using analytical models developed by Brinkworth [4], Olsson[7], Sandberg and Moshfegh [5] or He et al. [7].

In this non-stratified case, Eq. (24) gives $\Delta T_{\text {outside }}(\delta T=0)=0$ and consequently Eq. (10) leads to

$$
\Delta T_{\text {eff }}(\delta T=0)=\Delta T_{\text {inside }}(\delta T=0)=\Delta T_{0}
$$

\subsection{Case of a stratified ambient}

Considering now a positive stratification, $\delta T \geq 0$. For the same net heat input $\dot{Q}_{0}$ injected in the channel, the first law of thermodynamic leads now to

$$
\dot{Q}_{0}=\dot{m} C_{p} \Delta T_{\text {inside }} .
$$

By substituting Eq. (17) in Eq. (10) it falls

$$
\Delta T_{\text {inside }}=\Delta T_{\text {eff }}+H \delta T+\Delta T_{\text {outlet }}-\Delta T_{\text {inlet }} .
$$

For small $\delta T$, which corresponds to weakly stratified environment, $\Delta T_{\text {eff }}$ can be expressed using a Taylor development so that

$$
\Delta T_{e f f}(\delta T)=\Delta T_{e f f}(\delta T=0)+\Delta T_{e f f}^{\prime}(\delta T=0) \delta T+O\left(\delta T^{2}\right)
$$

Where $\Delta T_{e f f}^{\prime}$ is the first derivative of $\Delta T_{e f f}$ with respect to $\delta T$. 
Substituting Eq. (26) in Eq. (29) and factorising by $\Delta T_{0}$, Eq. (29) can be written as

$$
\Delta T_{e f f}(\delta T)=\Delta T_{0}(1+h(\delta T))
$$

with the limit of $h(\delta T)$ being 0 as $\delta T$ approaches 0 .

By substituting Eq. (30) in Eq. (28) and Eq. (28) in Eq. (27) it follows that

$$
\dot{Q}_{0}=\dot{m} C_{p}\left[\Delta T_{0}(1+h(\delta T))+H \delta T+\Delta T_{\text {outlet }}-\Delta T_{\text {inlet }}\right]
$$

Replacing $\dot{Q}_{0}$ by its expression in the case of a non-stratified ambient Eq. (25) and simplifying by $C_{p}$ yields to

$$
\dot{m}_{0} \Delta T_{0}=\dot{m}\left[\Delta T_{0}(1+h(\delta T))+H \delta T+\Delta T_{\text {outlet }}-\Delta T_{\text {inlet }}\right]
$$

Which can be rearranged as follows

$$
\frac{\dot{m}}{\dot{m}_{0}}=\frac{1}{1+h(\delta T)+\frac{H \delta T+\Delta T_{\text {outlet }}-\Delta T_{\text {inlet }}}{\Delta T_{0}}}
$$

At this stage the limit case when $h(\delta T) \approx 0$ is considered. This case is valid for small enough external thermal gradients. In that case Eq. (33) can be written as

$$
\frac{\dot{m}}{\dot{m}_{0}} \approx \frac{1}{1+S}
$$

in which $S$ is,

$$
S=\frac{H \delta T+\Delta T_{\text {outlet }}-\Delta T_{\text {inlet }}}{\Delta T_{0}}
$$

The non-dimensional stratification parameter $S$ represents the ratio of the external temperature increase between the open-boundaries of the channel in a stratified atmosphere, to the average internal temperature rise of the air flowing in the channel when the external atmosphere is at a uniform temperature.

\section{Experimental validation}

The theory developed in section 4 led to a non-dimensional formula that relates the mass flow rate to the external temperature gradient. However the evaluation of parameters $\Delta T_{\text {inlet }}$, $\Delta T_{\text {outlet }}$ and $\dot{m}_{0}$ is still to be addressed. Experimental data had been collected either from 
measurements made by the authors in an air channel or from experimental data obtained from the literature in which a water channel heated on both sides was studied.

\subsection{Experimental evaluation of $\Delta T_{\text {inlet }}, \Delta T_{\text {outlet }}$ and $\dot{m}_{0}$}

\subsubsection{Air channel 100W and 230W cases}

In the experimental apparatus in Fig. 1 thermocouples had been installed, as mentioned in section 2.2, at the inlet and at the edge of the outlet, in the mid plane $y / W=0.5$. Therefore the temperature of the entrained fluid at the inlet had been measured as well as the temperature of the air entrained by the column of air exiting the channel, so that each $\Delta T_{\text {inlet }}$ and $\Delta T_{\text {outlet }}$ could be evaluated. As the external temperature stratification $\delta T$ increased, $\Delta T_{\text {inlet }}$ and $\Delta T_{\text {outlet }}$ respectively decreased and increased. The experimental results are presented in Table 3 and show good agreement with the assessments given by Eq. (20) and Eq. (24) in section 4.2 .

Table 3 Experimental $\Delta T_{\text {inlet }}, \Delta T_{\text {outlet }}$, for the two data set $100 \mathrm{~W}$ and $230 \mathrm{~W}$

\begin{tabular}{lcc}
\hline$\dot{Q}_{t}(\mathrm{~W})$ & $\Delta T_{\text {inlet }}(\mathrm{K})$ & $\Delta T_{\text {outlet }}(\mathrm{K})$ \\
\hline $100 \mathrm{~W}$ & $-0.24 H \delta T$ & $0.32 H \delta T$ \\
$230 \mathrm{~W}$ & $-0.25 H \delta T$ & $0.37 H \delta T$
\end{tabular}

Since a non-stratified atmosphere is very hard to establish in a laboratory, the authors, could not directly measure $\dot{m}_{0}$. A first approach would be to calculate the intercept of the linear curves of best fit plotted in Fig.3. However, since extrapolation is also dangerous, another way is to rewrite Eq. (34) as

$$
\dot{m}_{0}=\frac{\dot{m}}{1-\frac{\dot{m} C_{p}\left(H \delta T+\Delta T_{\text {outlet }}-\Delta T_{\text {inlet }}\right)}{\dot{\mathrm{Q}}_{0}}}
$$

The solution of Eq. (36) can be obtained for any set of $\left(\dot{Q}_{0}, \dot{m}, \delta T\right)$ using either the expressions of $\Delta T_{\text {inlet }}$ and $\Delta T_{\text {outlet }}$ available in Table 3 or the coefficient assumed in section 4.2. Because whichever set is used, the values are similar, with a difference of less than $2 \%$ in the value of $\dot{m}_{0}$, in what follows, the coefficients assumed in section 4.2 will be used. At a given heat input $\dot{Q}_{0}$ the $\dot{m}_{0}$ obtained for different set of $(\dot{m}, \delta T)$ were not exactly the same. As a result the average and standard deviation $\sigma$ were calculated and since, as may be seen in Table 4, $\sigma$, is quite small, the values of $\dot{m}_{0}$ in Table 4 are used in the remainder of the paper. 
Table $4 \dot{m}_{0}$ and $\sigma$ for the two data set 100W and 230W

\begin{tabular}{lcc}
\hline$\dot{Q}_{t}(\mathrm{~W})$ & $\dot{m}_{0}(\mathrm{~kg} / \mathrm{s})$ & $\sigma(\mathrm{kg} / \mathrm{s})$ \\
\hline $100 \mathrm{~W}$ & 0.0174 & 0.0006 \\
$230 \mathrm{~W}$ & 0.0246 & 0.0014 \\
\hline
\end{tabular}

\subsubsection{Air channel 500W}

Only one measurement was available for the $500 \mathrm{~W}$ case, so that $\dot{m}_{0}$ could not be calculated as was done above. As a consequence a correlation was used instead. It is commonly accepted that $\dot{m}_{0}$ varies as a power of the net heat flux [11] so that $\dot{m}_{0} \sim \dot{q}_{0}^{\gamma}$ in which $\dot{q}_{0}$ $\left(\mathrm{W} / \mathrm{m}^{2}\right)$ is the heat flux associated to the net heat input $\dot{Q}_{0}$ and $\gamma$ is a coefficient that depends on the range of heat flux. Khanal and Lei [12] proposed that $\gamma=1 / 3$ for $R a<10^{8}$ and decreases to $\gamma=1 / 5$ for the range $10^{9}<R a<10^{11}$. Regarding the range of investigated Rayleigh numbers in Table 3, it is thus assume that a constant $\gamma=1 / 3$ is reasonable. Fig.5 is a plot of $\dot{m}_{0}$ as a function of net heat flux for $100 \mathrm{~W}, 230 \mathrm{~W}$ and $500 \mathrm{~W}$ obtained from the correlation $\dot{m}_{0}=0.0041 \dot{q}_{0}{ }^{1 / 3}$. Since this correlation fits the experimentally estimated values of $\dot{m}_{0}$ well for $100 \mathrm{~W}$ and $230 \mathrm{~W}$ cases, the value of $\dot{m}_{0}$ for the $500 \mathrm{~W}$ will therefore be used below.

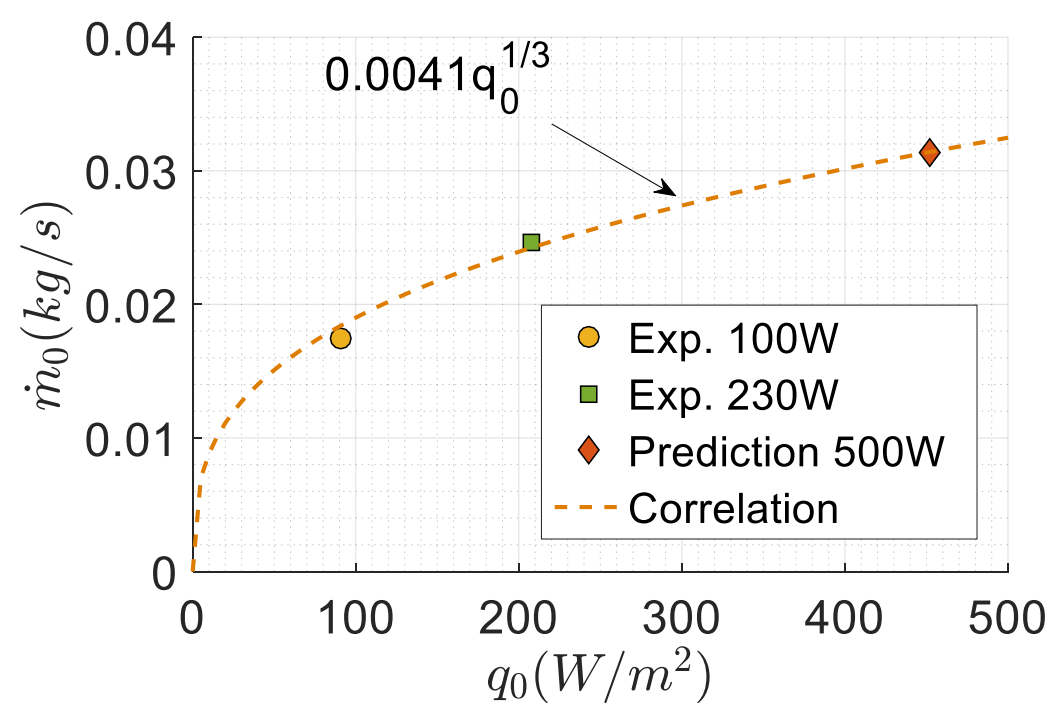

Fig.5. The mass flow rate in an isothermal atmosphere plotted against the heat flux for the cases $100 \mathrm{~W}$ and $230 \mathrm{~W}$. This figure also shows the correlation calculated from these cases and the prediction for $500 \mathrm{~W}$. 


\subsubsection{Water channel}

The experiments of Daverat et al. [31] had been carried out in a water channel, uniformly heated on both sides. The channel is $0.6 \mathrm{~m}$ height for $0.23 \mathrm{~m}$ wide, the two walls being $0.05 \mathrm{~m}$ apart and is located in a water tank of dimensions $1.50 \times 0.63 \times 0.23 \mathrm{~m}^{3}$. The net heat flux supplied to the channel was $190 \mathrm{~W} / \mathrm{m}^{2}$ and the corresponding Rayleigh number is $R a=2.9 \times 10^{4}$.

The ratio between the water tank height and the water channel height is similar to the ratio between the artificial ceiling height and the channel height presented in section 2.1, to that extent, the same values of $\Delta T_{\text {inlet }}$ and $\Delta T_{\text {outlet }}$ have been evaluated. They provide a measure of the mass flow rate $\dot{m}_{0}$ for a uniform temperature distribution outside the channel.

\subsection{Prediction of the non-dimensional mass flow rate}

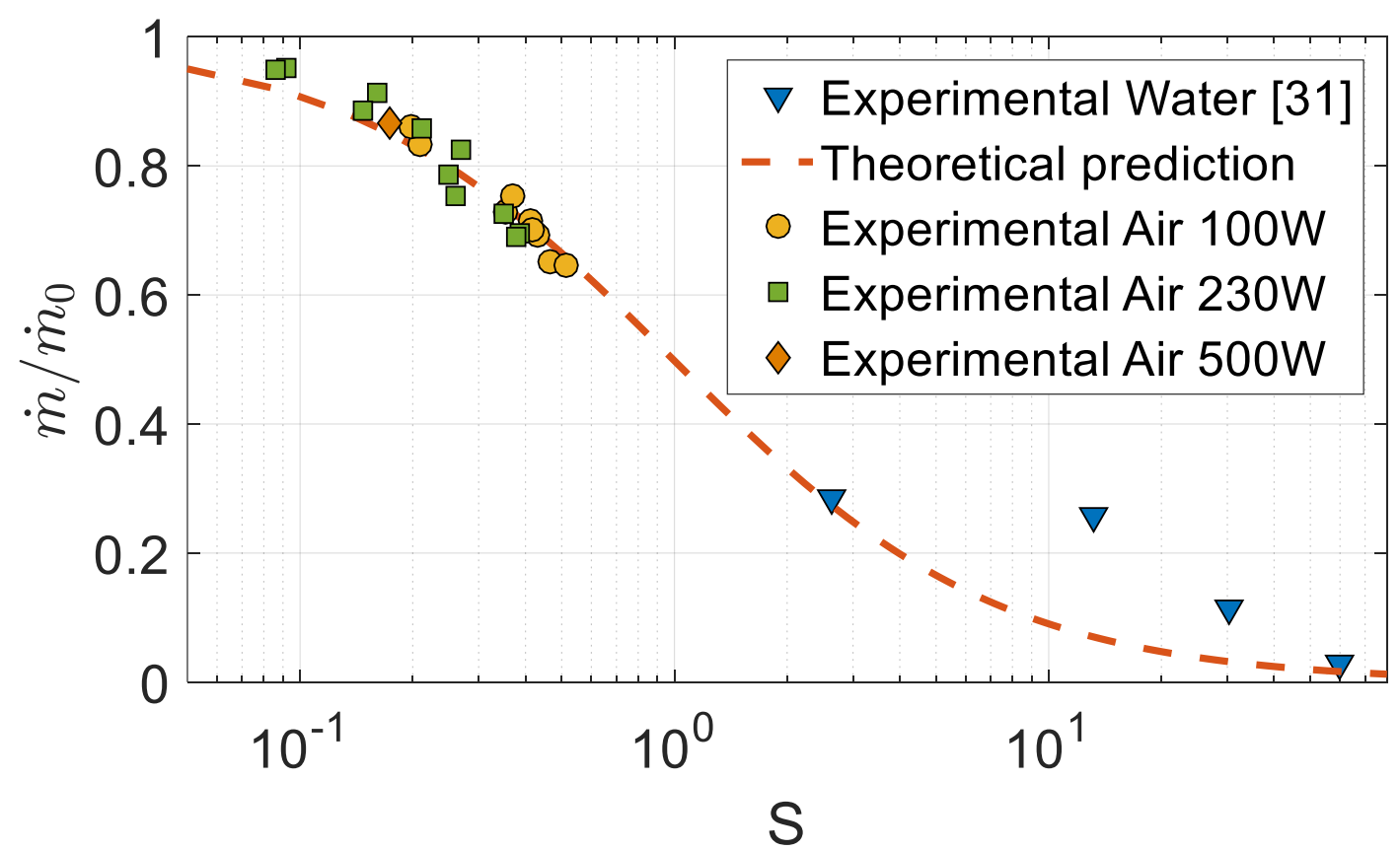

Fig. 7. Non-dimensional mass flow rate as a function of the non-dimensional stratification parameter $\mathrm{S}$

Experimental results for the cases obtained in the air channel $100 \mathrm{~W}, 230 \mathrm{~W}$ and $500 \mathrm{~W}$ as well as the experimental data of Daverat et al. [31] obtained in the water channel have been plotted in Fig.7.

The data closely cluster around the curve obtained from equation (34). The experimental results for the air channel, obtained in this work, are in excellent agreement with the 
theoretical prediction with a maximum relative deviation of less than $5 \%$. The maximum relative uncertainties, calculated from the experimental uncertainties, are around $12 \%$ on the ratio $\dot{m} / \dot{m}_{0}$ and around $5 \%$ on the stratification parameter $S$. There is also an excellent agreement with the first experimental data point obtained in the water channel by Daverat et al. [31] for $S=2.6$ which represents a stratification parameter five times higher than that obtained in the air channel. However the next two experimental points obtained in the water channel cannot be accurately predicted. This can be explained from the fact that, past a certain level of stratification, the water channel is not flowing full, as can be seen in Daverat et al. [31]. Instead, two separate boundary layer flows develop independently on each wall of the channel with an important quasi-stagnant region in the middle of the channel. In these conditions the channel flow cannot be considered as 1-D anymore and the model developed in section 4 in its present form is not suitable. In that specific case it would have been possible to derive a similar model as the one developed in section 4 by evaluating the temperature of the fluid feeding the boundary layer flows, from the temperature distribution in the quasi-stagnant zone. However this would require additional temperature data which is not provided by Daverat et al. [31].

Thus the proposed approximate analysis allows all the available experimental results, of the dependence of the mass flow rate induced by natural convection in a heated open channel on the external thermal gradient to be represented by a single curve.

\section{Discussion}

\subsection{Sensitivity of the induced mass flow rate to the external temperature gradient}

The sensitivity of the mass flow rate to the injected power, and more commonly to the Rayleigh number can be investigated by doing a basic sensibility analysis. As discussed in section 5.1.2, the mass flow rate evolves as a power of the Rayleigh number, so that $\dot{m}_{0} \approx$ $K_{1} R a^{\gamma}$. Despite that $\gamma$ varying as a function of Rayleigh number, $\gamma$ is between 0 and 1 so that $0<\gamma<1$. Given that the Rayleigh number is directly proportional to the net heat flux, Eq. (34) can be rewritten as

$$
\dot{m}=\frac{K_{1} R a^{\gamma}}{1+\frac{K_{2}\left(H \delta T+\Delta T_{\text {outlet }}-\Delta T_{\text {inlet }}\right)}{R a^{1-\gamma}}},
$$

where

$$
K_{2}=\frac{C_{p} K_{1} g \beta D^{4}}{A \alpha v k}
$$


Where $\mathrm{A}\left(\mathrm{m}^{2}\right)$ is the heated area. $K_{1}$ and $K_{2}$ are positive constant depending on the fluid properties and the channel geometry.

It can be seen from Eq. (37) that as the Rayleigh number increases, the external temperature gradient has a lower influence on the mass flow rate. This remark is consistent with the intuitive thought that, for a given fluid and channel geometry, the mass flow rate is relatively less affected by the external temperature distribution when the injected power increases.

\subsection{Toward better experimental/numerical comparison}

This work contributes to reducing the uncertainty usually attributed to experimental repeatability errors [15] as one source of potential discrepancies has been clearly identified and quantified.

This paper may help explaining some inadequacies found in the literature between experimental measurements and numerically generated or analytically obtained results. This could be the case for the work of Chen et al. [3] where they noted significant differences between the analytically predicted and the experimentally measured mass flow rate. In their work, the channel dimensions and injected powers are quite similar to those in the present study. However the room ceiling is $2.7 \mathrm{~m}$ lower. Consequently it is possible that stronger vertical temperature gradients occurred, inducing a decrease of the mass flow rate. Despite that the external temperature stratification was not reported by them, this analysis becomes even more credible when Chen et al.[3] noticed that the differences between analytically expected results and experimental data drastically reduce as the channel is inclined. Indeed as the channel is inclined, the external temperature drop at the channel open boundaries decreases as well, reducing its impact on the mass flow rate.

\subsection{Case of $\delta T<0$}

The focus of this paper has been on positive external temperature gradient, i.e. an ambient with a temperature increasing with height. However a similar theoretical development can be performed for negative gradient of temperature. In that case $S$ defined in equation (35) would become smaller than 1 which leads to $\dot{m}$ being larger than $\dot{m}_{0}$. This is interesting given that a negative stratification is actually the most common stratification occurring in the atmosphere. The expected results of such stratification would be to enhance the mass flow rate. This phenomenon had been observed, in a solar chimney by Haaf [39] but the lack of information in his paper regarding the external temperature gradient does not allow the analysis discussed in the present paper to be applied. 


\section{Conclusion}

In this study, the impact of the external temperature stratification on mass flow rate induced in a vertical uniformly heated channel was investigated experimentally and theoretically. The experimental data collected in an air channel is strongly correlated with the mass flow rate and the external temperature stratification for different injected net heat input of $100 \mathrm{~W}$ and $230 \mathrm{~W}$. In order to obtain a non-dimensional relation, to collapse on a single curve the results obtained at different injected powers and different external temperature gradients, a steady one-dimensional theory has been developed. This theoretical model is in excellent agreement with experimental data collected on an air channel, as well as some data, from the literature, obtained in a water channel.

More specifically, this model provides a way to estimate the impact of the external temperature gradient on the mass flow rate which, as a consequence, reduces the inadequacies observed between experimental measurements and analytically or numerically generated results. It therefore removes one of the potential sources of difference, usually neglected by the numericists. It demonstrates also that experimentalists have to provide additional information on the external thermal gradient while performing measurements on natural convection in vertical channels.

Moreover, despite the fact that the one-dimensional steady model has been developed without including the Prandtl or Rayleigh numbers, the agreement between the experimental and theoretical results, for various fluids, seems to suggest that these do not need to be included in the analysis as long as the channel is flowing full. Finally, the one-dimensional analysis suggests that a negative gradient of external temperature would increase the flow rate.

\section{Acknowledgment}

The authors would like to acknowledge KIC InnoEnergy which financially supported the mobility during which this article was written. 


\section{References}

[1] J. J. Bloem, "Evaluation of a PV-integrated building application in a well-controlled outdoor test environment," Build. Environ., vol. 43, no. 2, pp. 205-216, Feb. 2008.

[2] C.-O. Olsson, "Prediction of Nusselt Number and Flow Rate of Buoyancy Driven Flow Between Vertical Parallel Plates," J. Heat Transf., vol. 126, no. 1, pp. 97-104, Mar. 2004.

[3] Z. D. Chen, P. Bandopadhayay, J. Halldorsson, C. Byrjalsen, P. Heiselberg, and Y. Li, "An experimental investigation of a solar chimney model with uniform wall heat flux," Build. Environ., vol. 38, no. 7, pp. 893-906, Jul. 2003.

[4] B. J. Brinkworth, "Estimation of flow and heat transfer for the design of PV cooling ducts," Sol. Energy, vol. 69, no. 5, pp. 413-420, 2000.

[5] M. Sandberg and B. Moshfegh, "Buoyancy-induced air flow in photovoltaic facades: Effect of geometry of the air gap and location of solar cell modules," Build. Environ., vol. 37, no. 3, pp. 211-218, Mar. 2002.

[6] R. Khanal and C. Lei, "A scaling investigation of the laminar convective flow in a solar chimney for natural ventilation," Int. J. Heat Fluid Flow, vol. 45, pp. 98-108, Feb. 2014.

[7] G. He, J. Zhang, and S. Hong, "A new analytical model for airflow in solar chimneys based on thermal boundary layers," Sol. Energy, vol. 136, pp. 614-621, Oct. 2016.

[8] M. Raghib Shakeel, J. Al-Sadah, and E. M. A. Mokheimer, "Analytical and Numerical Modeling of Solar Chimney," J. Energy Resour. Technol., vol. 139, no. 3, pp. 031201031201-11, Feb. 2017.

[9] M. Miyamoto, Y. Katoh, J. Kurima, and H. Sasaki, "Turbulent free convection heat transfer from vertical parallel plates.," in The Eighth International Heat Transfer Conference, San Francisco, 1986, vol. Vol. 4, pp. 1593-1598.

[10] A. G. Fedorov and R. Viskanta, "Turbulent natural convection heat transfer in an asymmetrically heated, vertical parallel-plate channel," Int. J. Heat Mass Transf., vol. 40, no. 16, pp. 3849-3860, Oct. 1997.

[11] B. Moshfegh and M. Sandberg, "Investigation of fluid flow and heat transfer in a vertical channel heated from one side by PV elements, part I - Numerical Study," Renew. Energy, vol. 8, no. 1, pp. 248-253, May 1996.

[12] R. Khanal and C. Lei, "A numerical investigation of buoyancy induced turbulent air flow in an inclined passive wall solar chimney for natural ventilation," Energy Build., vol. 93, pp. 217-226, Apr. 2015.

[13] T. Yilmaz and S. M. Fraser, "Turbulent natural convection in a vertical parallel-plate channel with asymmetric heating," Int. J. Heat Mass Transf., vol. 50, no. 13-14, pp. 2612-2623, Jul. 2007.

[14] G. E. Lau, "Natural convection in building-integrated photovoltaic systems: a computational study," PhD Thesis, School of Mechanical and Manufacturing Engineering-UNSW, Sydney, 2013.

[15] E. Sanvicente, "Experimental investigation of thermal and fluid dynamical behavior of flows in open-ended channels: Application to Building Integrated Photovoltaic (BiPV) Systems," PhD Thesis, INSA de Lyon, Lyon, 2013.

[16] G. E. Lau, G. H. Yeoh, V. Timchenko, and J. A. Reizes, "Application of dynamic globalcoefficient subgrid-scale models to turbulent natural convection in an enclosed tall cavity," Phys. Fluids, vol. 24, no. 9, p. 094105, Sep. 2012.

[17] A. Zoubir, "Etude des transferts thermo-convectifs dans un canal semi-ouvert: Application aux façades type double-peau," PhD Thesis, INSA de Lyon, Lyon, 2014.

[18] X. Cheng and U. Müller, "Turbulent natural convection coupled with thermal radiation in large vertical channels with asymmetric heating," Int. J. Heat Mass Transf., vol. 41, no. 12, pp. 1681-1692, Jun. 1998. 
[19] O. Manca and S. Nardini, "Thermal Design of Uniformly Heated Inclined Channels in Natural Convection with and without Radiative Effects," Heat Transf. Eng., vol. 22, no. 2, pp. 13-28, Mar. 2001.

[20] A.-M. Dalbert, F. Penot, and J.-L. Peube, "Convection naturelle laminaire dans un canal vertical chauffe a flux constant," Int. J. Heat Mass Transf., vol. 24, no. 9, pp. 14631473, Sep. 1981.

[21] G. Desrayaud and G. Lauriat, "Flow reversal of laminar mixed convection in the entry region of symmetrically heated, vertical plate channels," Int. J. Therm. Sci., vol. 48, no. 11, pp. 2036-2045, Nov. 2009.

[22] O. A. Tkachenko et al., "Numerical and experimental investigation of unsteady natural convection in a non-uniformly heated vertical open-ended channel," Int. J. Therm. Sci., vol. 99, pp. 9-25, Jan. 2016.

[23] G. Desrayaud et al., "Benchmark solutions for natural convection flows in vertical channels submitted to different open boundary conditions," Int. J. Therm. Sci., vol. 72, pp. 18-33, Oct. 2013.

[24] M. Sandberg and B. Moshfegh, "Investigation of fluid flow and heat transfer in a vertical channel heated from one side by PV elements, part II - Experimental study," Renew. Energy, vol. 8, no. 1, pp. 254-258, May 1996.

[25] E. Sanvicente, S. Giroux-Julien, C. Ménézo, and H. Bouia, "Transitional natural convection flow and heat transfer in an open channel," Int. J. Therm. Sci., vol. 63, pp. 87-104, Jan. 2013.

[26] R. Cheesewright, "Natural convection from a plane, vertical surface in non-isothermal surroundings," Int. J. Heat Mass Transf., vol. 10, no. 12, pp. 1847-1859, Dec. 1967.

[27] Y. Jaluria and B. Gebhart, "Stability and transition of buoyancy-induced flows in a stratified medium," J. Fluid Mech., vol. 66, no. 3, pp. 593-612, Nov. 1974.

[28] C. Garnier, "Modélisation numérique des écoulements ouverts de convection naturelle au sein d'un canal vertical asymétriquement chauffé," PhD Thesis, Université Pierre et Marie Curie - UPMC (Paris 6), Paris, 2014.

[29] D. Ramalingom and A. Bastide, "Impact of external surroundings on natural convection in a vertical channel asymmetrically heated," in Proceedings of European Congress on Computational Methods in Applied Sciences and Engineering, Crete, Greece, 2016.

[30] W. Haaf, K. Friedrich, G. Mayr, and J. Schlaich, "Solar Chimneys Part I: Principle and Construction of the Pilot Plant in Manzanares," Int. J. Sol. Energy, vol. 2, no. 1, pp. 320, Jan. 1983.

[31] C. Daverat, H. Pabiou, H. Bouia, S. Xin, and C. Menezo, "Convection naturelle dans un canal vertical en eau avec chauffage pariétal : influence de la stratification," in 20ième Congrès Français de Mécanique, Besançon, France, 2011, pp. 162-167.

[32] G. Polidori, S. Fatnassi, R. Ben Maad, S. Fohanno, and F. Beaumont, "Early-stage dynamics in the onset of free-convective reversal flow in an open-ended channel asymmetrically heated," Int. J. Therm. Sci., vol. 88, pp. 40-46, Feb. 2015.

[33] C. Daverat, Y. Li, H. Pabiou, C. Ménézo, and S. Xin, "Transition to turbulent heat transfer in heated vertical channel - Experimental analysis," Int. J. Therm. Sci., vol. 111, pp. 321-329, Jan. 2017.

[34] M. Raffel, C. E. Willert, S. T. Wereley, and J. Kompenhans, "PIV Recording Techniques," in Particle Image Velocimetry, Springer Berlin Heidelberg, 2007, pp. 97121.

[35] W. Thielicke and E. Stamhuis, "PIVlab - Towards User-friendly, Affordable and Accurate Digital Particle Image Velocimetry in MATLAB," J. Open Res. Softw., vol. 2, no. 1, Oct. 2014.

[36] J. Vareilles, "Étude des transferts de chaleur dans un canal vertical différentiellement chauffée : application aux enveloppes photovoltaïques/thermiques," PhD Thesis, University Lyon 1, Lyon, 2007.

[37] D. D. Gray and A. Giorgini, "The validity of the boussinesq approximation for liquids and gases," Int. J. Heat Mass Transf., vol. 19, no. 5, pp. 545-551, May 1976. 
[38] O. Manca, B. Morrone, and V. Naso, "A numerical study of natural convection between symmetrically heated vertical parallel plates," in XII Congresso Nazionale UIT, 1994, pp. 379-390.

[39] W. Haaf, "Solar Chimneys," Int. J. Sol. Energy, vol. 2, no. 2, pp. 141-161, Jan. 1984. 